\title{
Business-IT Alignment in the Era of Digital Transformation: Quo Vadis?
}

\author{
Gideon Mekonnen Jonathan \\ Stockholm University \\ gideon@dsv.su.se
}

\author{
Lazar Rusu \\ Stockholm University \\ $\underline{\text { lrusu@dsv.su.se }}$
}

\author{
Erik Perjons \\ Stockholm University \\ perjons@dsv.su.se
}

\begin{abstract}
For the last four decades, the alignment of business and IT strategies also referred to as business-IT alignment (BITA), has been recognised as one of the top concerns for leaders. The current digital transformation journey undertaken by most organisations, however, triggered a new approach to planning and executing business and IT strategies as well as pursuing BITA. A systematic literature review is conducted to capture the paradigmatic shift in research and practice. A total of 94 articles published between 2014 and 2018 were identified searching through databases known to index reputable IS journals and conference proceedings. The analysis of the review revealed the continued conceptual debate on BITA construct as well as new research topics. The significance of digital strategy, enterprise architecture models, as well as intelligent IT systems to enable elicitation, implementation and assessment of activities enabling BITA are garnering the attention of researchers. Potential research directions are presented.
\end{abstract}

\section{Introduction}

The important role of business-IT alignment (BITA), defined as the "application of Information Technology (IT) in an appropriate and timely way, in harmony with business strategies, goals and needs" [1, p. 3] has been recognised for the last four decades. In addition to the surveys which place BITA constantly among the top concerns for IT leaders [2], it also continues to be ranked as one of the most researched topics in the IS and cognate domains [3-5]. Given the empirical evidence confirming the positive relationship between BITA and organisational performance, the attention rendered to BITA is justified. As noted in the literature, BITA was conceptualised as the fit between the IT and business strategies [6]. However, other studies contend that this strategic alignment view only captures the partial fit and integration needed between IT and the rest of the business. For instance, Henderson and Venkatraman [7] argue that the alignment between the IT and business strategies need to be complemented with the fit between business- and IT infrastructures, and processes.

Even though achieving and maintaining BITA has never been easy since the proliferation of IT, the current business environment demands have made BITA more challenging. Yeow et al. [8] attribute this development to the rapid internal (organisational) and external environmental changes that organisations need to navigate through. Among these changes triggered by environmental dynamism is the digital transformation journey many firms are undertaking. Berman [9, p. 17] defines digitalisation (also referred to as 'digital transformation' in this study) as "a set of complementary activities-reshaping customer value propositions and transforming their operations using digital technologies for greater customer interaction and collaboration". The increasingly digitalised operations in many firms require adjustments and reconfigurations of different elements that influence BITA [8]. These changes have several implications on how IT is viewed, and how operations and processes are designed. As Sia et al. [10] put it, the traditional view that articulates business and IT strategies separately is losing ground for a more integrated approach that recognises embeddedness of IT with the whole organisation. In particular, this development has created a situation where the firms business and IT strategies are indistinctly fused to form what is becoming a "digital strategy" [11].

Despite its benefits, digitalisation is found to bring the challenge of reaching BITA to a new level. According to Kahre et al. [12], $48 \%$ of the CIOs in US firms spend most of their time attempting to align their IT strategies with the overall organisational objectives. Considering the new trend of digitalisation, researchers argue that a paradigmatic shift is required to further our understanding on how to meet the challenges of IT management in general and the issue of BITA in particular [8,12-14]. While the literature on BITA studies is rich and mature, up-to-date and comprehensive review of the recent studies reflecting the new developments and trends is deemed necessary. This applies to 
practice-oriented propositions to foster BITA as well as appropriate research approaches to investigate the BITA issues in the era of digital transformation. The goal of this study is threefold: (1) to provide an overview of the main topics of recent BITA studies, (2) to highlight the findings of these studies, and (3) to identify research gaps that could be addressed in future research.

To reach these goals, the following research questions are used to guide in the identification of relevant literature as well as in the systematic presentation of the review: Which organisational and external factors influencing BITA are raised in the recent BITA studies, and what are the research approaches applied in these studies? and What conclusion can be drawn from the recent BITA studies, and what are the future research directions?

The remainder of this paper is structured as follows: The subsequent section describes the research methodology. The third section presents the result and analysis of the review according to the research questions. Finally, the conclusion presents the summary of the findings, limitation of the study, and suggestions for future research.

\section{Research Methodology}

This study utilises a systematic literature to identify and analyse the extant literature to derive a possible research direction. Webster and Watson [15] argue that systematic literature reviews are invaluable for researchers as they provide a structured account of past studies. Established literature review guidelines in the IS discipline $[15,16]$ were followed to identify, classify and summarise the recent five years' BITA studies (i.e. between 2014 and 2018).

\subsection{The literature selection and data extraction}

The search for literature begun with the identification of journals and conference proceedings publishing BITA studies. As reputable journals and conferences are known to be useful sources of articles in the desired area of study $[15,16]$, the eight IS Senior Scholars Basket of Journals, as well as the five reputable, IS international conference proceedings (AMCIS, ECIS, HICSS, ICIS, PACIS) were targeted. The Australian Computer Research and Education conference portal (CORE) were used to identify the list of conference proceedings with 'A' ranking. The International Journal of IT/Business Alignment and Governance was also selected for the initial literature search as it publishes articles focusing on BITA.

Databases known to index the selected publications were identified. In total, eight scientific databases-ACM Digital library, AIS eLibrary, Business Source Premier,
EBSCO Host, Emerald, IEEEXplore, ISI web of Knowledge, and SpringerLink-were searched for combinations of: "IT business", " IS business", " IT", “ IS", " strategic", " Information technology", “ Information system", " IT strategy", " business strategy", "Information technology strategy", "Information system strategy" and "alignment" or " fit" or " aligning" or " align".

BITA is one of the most extensively researched topics in the IS and related research areas. However, to make sure only a reasonable volume of literature sample that is manageable for the analysis is selected, the search was limited to the last five years (2014-2018). The final list of articles also includes studies that are published elsewhere but identified through backward- and forward search as suggested by Okoli [16].

Complete peer-reviewed articles focusing on BITA satisfy the inclusion criteria. The following exclusion criteria are applied: research-in-progress articles, book chapters, incomplete articles and articles published in languages other than English. Figure 1 shows the literature search process.

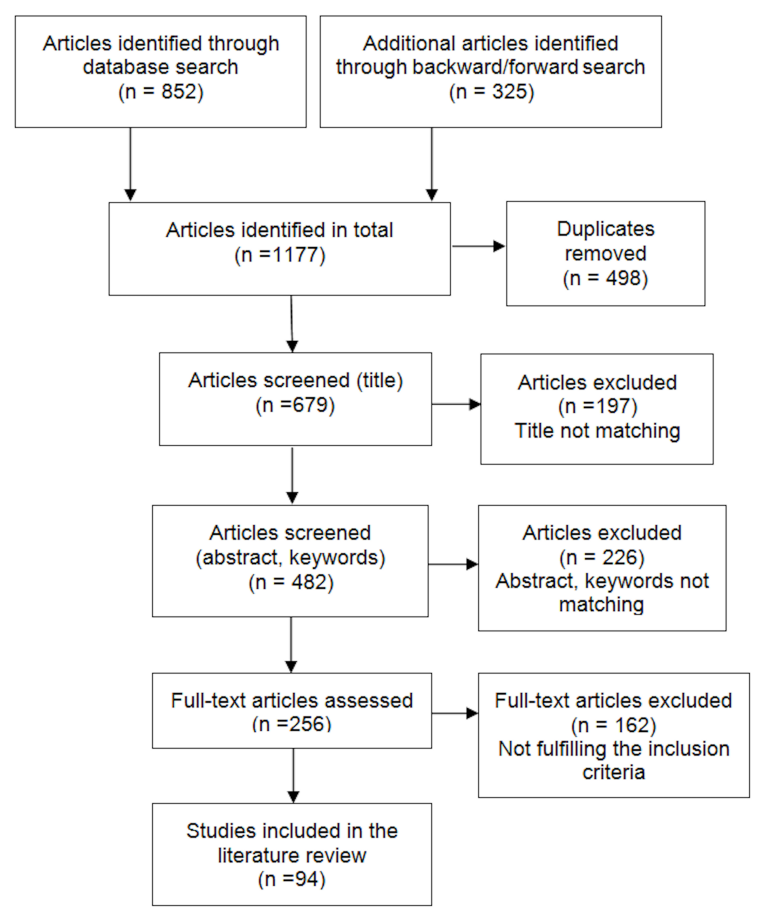

Figure 1. The literature search process.

The search for literature resulted in the identification of a total of 94 articles published in 31 journals $(n=45)$ and 26 conference proceedings $(n=49)$. To obtain the main message from the articles and answer the research questions, the following data is extracted, labelled and coded: publication type (journal or conference proceedings), authors, research approaches, 
main research topics, research questions / hypotheses / objectives, findings and conclusions. The full-text of the articles selected were revised carefully to appropriately analyse and categorise the contents into themes. This literature review is concept-centric [15] where the concepts guide the structure of the synthesis and presentation.

\section{Results and Discussion}

The literature review illustrates the continued attention rendered to BITA among IS researchers. To respond to the research questions formulated, the following sections present the findings of the systematic review starting with the common research topics followed by the research approaches employed by the studies included in the review.

\subsection{The conceptual debate}

The first main finding of this review is that there is still an ongoing debate among scholars about BITA conceptualisation. The discussion is not restricted only in the conceptual studies, but it is also reflected in the choices of research methods in the empirical studies. One of the criticisms on the previous BITA studies is the lack of consistent definition and conceptualisation of the phenomenon. According to Gerow et al. [3], this inconsistency has been the source of confusion as well as contradictory findings in the empirical studies. The results of this review also indicate that the debate on how to best address BITA issues has continued. For instance, the literature provides different dimensions that can help us better understand BITA and find appropriate ways to achieve it. The four dimensions of BITA-strategic alignment, intellectual alignment, structural alignment, as well as the social alignment-have been recognised in the IS literature [17]. However, there seems to be disproportional attention on some of these dimensions. Zhou et al. [18] argue that the focus of most of BITA studies have been on how organisations at the top level formulate their IT and business strategies (also referred to as strategic IS alignment) while little attention has been given to alignment at operational and tactical levels. However, the findings of empirical studies suggest that most of the BITA barriers are at the tactical and operational levels than the strategic level [17-24]. To address BITA issues at different levels, some of the reviewed studies have proposed different approaches. For instance, the method designed by Kivijrvi [25] provides organisations with a decision support method that could be implemented to support various processes within an organisation to improve alignment.

The second conceptual debate that seems to dominate the extant literature is whether BITA should be seen as a static position or a process [4,5]. Luftman et al. [26] criticise previous studies for their static view of BITA. However, the findings of the recent studies seem to have converged onto the conceptualisation that BITA should be viewed as a continuous process that needs to be monitored and adjusted according to the changes in the internal and external environment. Many of the studies reviewed also seem to recognise BITA as a process rather than as an outcome at the end (e.g., [8,19,27-31]). As pointed by Amarilli et al. [32], the different view of BITA as a state or a process depends on the choice of theory chosen by researchers. For instance, those who view organisations as a complex system and adopt related theories view BITA as a process. Even though most of the identified articles do not explicitly state the theoretical underpinnings, the resource-based view [8,33-37], social network theory [31], social-capital theory [17, 38-40], complex systems theory $[30,37]$ seem to be the common theories in recent BITA studies.

Studies subscribing to the state perspective of BITA attempt to identify lists of factors that enable or hinder BITA [4]. Even though the influence of internal (organisational) and external environmental factors are acknowledged, most of the reviewed articles focus on the internal factors (e.g., [21, 33, 38, 41-43]). On the other hand, majority of the studies with the process perspective put forward propositions to foster continuous alignment process. These studies adopt some forms of a co-evolutionary approach transcending the business and IT domains to explore different mechanisms that are invaluable for organisations to reach an aligned position (e.g., $[29,32,37,44-47])$.

\subsection{Business-IT alignment models}

Since the original strategic alignment model [7] appeared decades ago, a number of models and frameworks have been proposed with the interest of providing clear conceptual understanding of BITA. A closer look into the articles included in the review indicates that 20 of the 94 studies are set out at developing new models (e.g., [20,48-57]) or modifying previously developed models to fit the different organisational settings (e.g., [58-62]).

Even though these models are designed to help us further our understanding of BITA and help organisations make assessments and identify factors that can improve alignment, there are researchers casting doubt on how well these models reflect the reality in today's firms. For instance, Reynolds and Yetton [34] argue that BITA has increasingly become more complex and challenging making these models too simplistic to apply. The literature offers some antecedents for this development. 
First, today's organisations are moving away from a single or few lines of businesses towards becoming large organisations consisting of multiple businesses with diverse interests. This complexity recognised in many studies, for instance, [11, 33, 45, 58, 63-67] has brought about the need for complex organisational structures as well as the introduction of IT solutions embedded with the business strategies. Second, organisations are operating in a fast paced business environment that requires continuous adjustments [52,66,68-71].

El-Mekawy et al. [72] argue that the emphasis on different elements, for instance, concepts/aspects of alignment in the various models in the literature has resulted in confusion among researchers and practitioners. According to Reynolds and Yetton [34], the arguments in the existing literature are convincing enough to revisit our assumptions on BITA. The new model developed by the authors is based on three propositions for today's multi-business organisations. The first two propositions are related to how BITA occurs in an organisation (at corporate and at the strategic business unit level) by looking into IT and business strategies at different levels. The third proposition recognises the dynamic nature of BITA. Other new models have also been proposed recently (e.g., [20, 44, 50]).

\subsection{BITA and organisational performance}

Studies investigating the relationship between BITA and organisational performance are not new. In fact, most IS researchers attribute the attention given to BITA to its influence on overall organisational performance $[3,5]$. Consistent with the previous literature reviews, the findings of the studies reviewed seem to suggest BITA improves organisational performance [19, 21, 24, 25, 32, 34, 38, 49, 60, 71, 73-77]. While most studies investigating BITA and its merits focus on overall financial performance or the realised value of IT, some studies have explored specific BITA outcomes. For instance, the influence of BITA on the creation of integrated knowledge on information security risks and controls has been confirmed [38, 78-80]. Information security knowledge among employees is also found to improve the information security system effectiveness, which in turn is favourably reflected on organisational performance.

The findings from the reviewed articles also seem to confirm the moderating effect of BITA. For instance, $\mathrm{Wu}$ et al. [35] argue that the improved performance associated with different IT governance mechanisms is only observed when it is mediated by the alignment between business and IT strategies. The study by Kude et al. [33] suggest that organisations with effective
IT governance capabilities are likely to achieve BITA. According to the authors, the increased awareness for IT costs, and the personal accountabilities associated with IT processes and IT roles result in not only more aligned position but the improved resource relatedness as well. Another study confirms the moderating role of BITA between innovation and IT governance as well as the IT competence of top leaders [41].

The findings of the empirical studies in the reviewed literature indicate that the positive relationship between BITA and organisational performance is replicated in different types of organisations. For instance, in multi-business organisations, Queiroz et al. [81] found that the performance of business units is influenced by the BITA maturity at the corporate and business unit levels. Baker and Niederman [76] also explored the role of BITA for successful IS integration in mergers and acquisitions. On the other hand, the influence of BITA on fostering future business value has also been one of the topics studied. Rahrovani et al. [82] argue that future IT investment plans need to be part of the BITA equation if organisations are to gain value from their IT projects. This is consistent with similar findings confirming the favourable influence of BITA on IT projects $[53,68,83$, 84].

Even though most of the findings of the studies seem to confirm the positive influence BITA has on organisational performance, there are also studies calling on for more studies to explore this relationship in different organisational settings including IT governance mechanisms, organisational size and organisational structures $[85,86]$. The survey to explore the influence of BITA on organisational performance by Queiroz [46] resulted in contradictory findings. According to the study, BITA maturity, in addition to the choice of strategic orientation of firms, determine whether improved performance is realised.

\subsection{Alignment-Agility paradox}

The extant literature shows that the intellectual dimension of alignment has been the focus of many researchers while the social dimension is rarely pursued $[31,39,87]$. This limited attention of the social dimension of alignment is considered to be one of the possible reasons for what is known as an alignment-agility paradox. Alignment-agility paradox refers to the unintended result of business-IT alignment that results in rigidity resulting from resource commitments and embedded IT processes $[52,87]$.

Even though the significance of organisational agility is recognised by most of the studies reviewed [13, 14, $18,28,29,31,42,52,70,71,75,77,87]$, the findings indicate that the topic did not attract the attention 
of BITA researchers until recently. Organisations in todays turbulent business environment could benefit if they successfully manage to reach alignment, which is appropriate to provide organisational agility [18]. The message shared by these studies is that BITA should not create organisational rigidity preventing the deployment of resources in an appropriate manner [34]. The review of the identified literature shows a two-directional relationship between BITA and organisational agility. The first set of studies attempt to explore whether organisational agility helps firms to achieve BITA. For instance, Jorfi et al. [28] argue that organisations with agility are more likely to have reached BITA. One of the remaining studies [42] was set out to establish whether agility of IT infrastructures improves BITA. The findings reveal that only one of the four components of agility, i.e. compatibility influences BITA. However, connectivity, modularity, and IT personnel flexibility seem to have little effect on BITA. The second set of studies explore whether BITA plays a role in organisational agility. Panda and Rath [29] argue that organisations need to look at organisational agility as a means of appropriately responding to the changes in their business processes or to cope with the changes in the market. In a highly uncertain environment, BITA is found to have a more significant influence on market responsive agility but not on business process agility. However, Liang et al. [87] found only social alignment to facilitate organisational agility while intellectual alignment impedes it. On the other hand, there are few studies suggesting the critical role of operational alignment to be the driver of organisational agility $[18,23,75]$. To this end, new enterprise information systems have been proposed to facilitate a continuous operational alignment (e.g., [13]).

\subsection{Enablers and inhibitors of BITA}

As acknowledged in the recent BITA literature, today's competitive and dynamic business environment required the adoption of information technology which is capable of driving the business strategy of an organisation to tap innovation and achieve competitive advantage [26, 88]. However, achieving and maintaining BITA remains to be a challenging task. Consistent with previous findings [89], different factors that could enable or inhibit BITA are identified. The result of the analysis seems to confirm the various internal (organisational) as well as external factors identified in the previous studies. For instance, lack of communication at different organisational levels [23], involvement of top leaders on IT projects [75, 84, 90], Partnership relationship between business and IT domains [14,91,92], relational leadership [38], commitment [73,80,91], organisational structure [93], organisational culture [59, 67, 94], IT governance arrangements $[25,33-35,41,57,75,95-97]$ are found to determine whether an organisation achieves BITA. Even though most of the BITA barriers are not new, a closer look into the studies reviewed indicate that a new list of questions are being asked in line with the emerging organisational forms. For instance, how could organisations adopting cloud computing [45, 54, 64, 98], robot process automation [98] or organisations with legacy systems [99] realise BITA? Studies on enablers of BITA found enterprise architecture to be the answer to many of the challenging issues $[13,20,44,50,55$, $60,62,70,85,88,100,101]$. The findings suggest that emotional intelligence [102], social structure [31], and digital strategy [8] influence BITA favourably.

\subsection{Research approaches in BITA studies}

The identified articles are broadly categorised as empirical and conceptual [103]. A closer look into the research approaches of the selected studies shows that case studies are by far the most preferred research strategy. Surveys are the second most adopted research strategies. In contrast with previous literature reviews (for instance, [104]), there is an increase in the number of studies following the design science research.

Chan and Reich [4] argue that the findings of BITA studies in one setting might not apply to another organisation in a different environment due to the number of variables that influence BITA. It is, therefore, appropriate to have an overview of the research settings of studies identified for the review. Both small and medium (e.g., [43, 74, 86, 105-107]) as well as large organisations (e.g., $[45,73,81,93,108]$ ) have been investigated as size of an organisation is found to affect the adoption of information systems which in turn has implication for BITA. For instance, BITA is found to be challenging for SMEs as a result of scarce financial resources as well as limited knowledge of IT and time constraints. The most interesting contextual differences noted in the identified studies is the origin of the empirical studies. Even though ten studies did not mention the country of study, a handful of developed countries have produced most of the empirical studies. For instance, more than $25 \%$ of the studies were conducted in Sweden, Germany, and the USA. On the other hand, 14 of the 84 empirical studies were from the developing countries (e.g., [29, 63, 70, 77, 106, 109, 110]). Despite the recognised differences between the private and public organisations $[104,111]$, a closer look into the identified studies indicate that only few empirical studies $[48,56,112]$ were conducted in public organisations. 


\section{Conclusion}

This study examined the current research agenda, research methods, as well as approaches to addressing BITA issues in this digital transformation era. The analysis of the study identifies five different BITA issues in the extant literature-conceptual debates on BITA construct, alignment models, the relationship between BITA and organisational performance, alignment maturity paradox, as well as BITA enablers and inhibitors.

The debate on BITA construct is not limited to conceptual studies. Empirical studies continue to employ different research approaches consistent with the various BITA dimensions and concepts. Even though authors still argue the importance of contextual differences in BITA studies justifying the choice of case studies to make in-depth analysis, more surveys and design science research methods are making their way into BITA studies. Given the current trend of digital transformation and introduction of innovative use of IT across industries, researchers are resorting to new research approaches. For instance, in addition to single and multiple case studies, a qualitative comparative analysis is being applied to investigate BITA in different organisational settings and consolidate these findings. Another related observation from the conceptual debate, in contrast with previous reviews, for instance, [5], is that the increasing focus of BITA studies in addressing practical issues that can be invaluable for organisations in their attempt to reach and maintain BITA. In addition to the case studies and surveys aiming to identify antecedents and establish relationships between different factors that influence BITA, different models and frameworks are proposed to assess BITA and take steps to improve its maturity in different contextual settings. The propositions address the various BITA issues across different sectors (banking, manufacturing, communication, healthcare, education, etc). However, the lack of studies is still noticeable in some information intensive sectors. For instance, consistent with previous studies (e.g., [104, 111, 113]) only a few studies have looked into BITA in the public organisations context. On the other hand, the handful of studies on BITAs relationship with organisation size $[43,74,105,106,112]$ present contradictory findings that need to be corroborated in future studies.

The result of the review also reveals that there is a shift from a static view of BITA to a recognition of its dynamic nature. This paradigmatic shift is necessary to respond to the changes required in response to the fast pace changes in IT and business environment. Organisational agility and how it relates to BITA is a timely topic that has not attracted the attention it deserves. As pointed out in most of the studies aimed at developing enterprise architecture models and designing of intelligent IT systems that make the elicitation, implementation and assessment of activities that improve BITA, there is a need for organisations to recognise the strategic role of IT. The result of the study also found that, digitalisation in general and digital strategy formulation, in particular, is challenging to be in the alignment equation. One of the recognised reasons is that organisations still find it challenging to articulate their digital strategies in today's dynamic environment mired with a swift change in technology and demand from their customers. Future research needs to investigate the relationship between digital strategy planning and BITA maturity.

Other unexplored research areas have also been identified. For instance, the importance of entrepreneurial strategy and its influence on BITA is a topic which has not attracted the researchers attention yet. Again, this is related to the lack of BITA studies in the small and medium enterprises, as indicated in many of the reviewed studies. There is also a lack of studies relating to BITA in mergers and acquisitions. This is one of the critical organisational contexts lacking from the extant literature. Baker and Niederman [76] found that BITA plays a vital role in whether mergers and acquisitions successfully manage firm integration. Among other things, the poorly accounted IT assets and lack of tactical actions supporting emergent business and IT strategies are found to influence BITA.

The limitations of this study relate to the method used to select the relevant literature. As a phenomenon transcending the IS and other related disciplines, BITA has been defined differently, resulting in the use of different terms for describing it. The use of keywords to search for relevant literature might not have captured all studies that would have provided additional insights. Future reviews could apply other methods to overcome the shortcoming of the review. Searching in other databases that index IS related research areas might also reveal additional studies to further our understanding of BITA.

\section{References}

[1] J. Luftman, "Assessing business-IT alignment maturity," Communications of the Association for Information Systems, vol. 4, no. 1, pp. 1-51, 2000.

[2] L. Kappelman, R. Torres, E. McLean, C. Maurer, V. Johnson, and K. Kim, "The 2018 SIM IT issues and trends study," MIS Quarterly Executive, vol. 18, no. 1, pp. 51-84, 2019.

[3] J. E. Gerow, V. Grover, and J. Thatcher, "Alignment's nomological network: Theory and evaluation," Information \& Management, vol. 53, no. 5, pp. 541-553, 2016.

[4] Y. E. Chan and B. H. Reich, "IT alignment: What have 
we learned?," Journal of Information technology, vol. 22, no. 4, pp. 297-315, 2007.

[5] A. Karpovsky and R. D. Galliers, "Aligning in practice: From current cases to a new agenda," Journal of Information Technology, vol. 30, no. 2, pp. 136-160, 2015.

[6] B. H. Reich and I. Benbasat, "Measuring the linkage between business and information technology objectives," MIS Quarterly, vol. 20, no. 1, pp. 55-81, 1996.

[7] N. Venkatraman and J. Henderson, "Strategic alignment: Leveraging information technology for transforming organizations," IBM systems journal, vol. 32, no. 1, pp. 4-16, 1993.

[8] A. Yeow, C. Soh, and R. Hansen, "Aligning with new digital strategy: A dynamic capabilities approach," The Journal of Strategic Information Systems, vol. 27, no. 1, pp. 43-58, 2018.

[9] S. J. Berman, "Digital transformation: opportunities to create new business models," Strategy \& Leadership, vol. 40, no. 2, pp. 16-24, 2012.

[10] S. K. Sia, C. Soh, and P. Weill, "How DBS bank pursued a digital business strategy," MIS Quarterly Executive, vol. 15, no. 2, pp. 105-121, 2016.

[11] R. D. Galliers, "In celebration of diversity in information systems research," Journal of Information Technology, vol. 26, no. 4, pp. 299-301, 2011.

[12] C. Kahre, D. Hoffmann, and F. Ahlemann, "Beyond business-IT alignment-digital business strategies as a paradigmatic shift: A review and research agenda," in Proceedings of the 50th Hawaii International Conference on System Sciences, 2017.

[13] K. Hinkelmann, A. Gerber, D. Karagiannis, B. Thoenssen, A. Van der Merwe, and R. Woitsch, "A new paradigm for the continuous alignment of business and IT: Combining enterprise architecture modelling and enterprise ontology," Computers in Industry, vol. 79, pp. 77-86, 2016.

[14] A. Manfreda and M. Indihar Štemberger, "Establishing a partnership between top and IT managers: A necessity in an era of digital transformation," Information Technology \& People, vol. 40, no. 2, pp. 16-24, 2018.

[15] J. Webster and R. T. Watson, "Analyzing the past to prepare for the future: Writing a literature review," MIS quarterly, vol. 26, no. 2, pp. xiii-xxiii, 2002.

[16] C. Okoli and K. Schabram, "A guide to conducting a systematic literature review of information systems research," Sprouts: Working Papers on Information Systems, vol. 10, no. 26, pp. 1-50, 2010.

[17] H.-T. Wagner, D. Beimborn, and T. Weitzel, "How social capital among information technology and business units drives operational alignment and IT business value," Journal of Management Information Systems, vol. 31, no. 1, pp. 241-272, 2014.

[18] J. Zhou, G. Bi, H. Liu, Y. Fang, and Z. Hua, "Understanding employee competence, operational IS alignment, and organizational agility: An ambidexterity perspective," Information \& Management, vol. 55, no. 6, pp. 695-708, 2018.

[19] O. Avila, V. Goepp, and F. Kiefer, "Addressing alignment concerns into the design of domain-specific information systems," Journal of Manufacturing Technology Management, vol. 29, no. 5, pp. 726-745, 2018.
[20] P. Bhattacharya, "Modelling strategic alignment of business and IT through enterprise architecture: Augmenting archimate with bmm," Procedia Computer Science, vol. 121, pp. 80-88, 2017.

[21] S. Charoensuk, W. Wongsurawat, and D. B. Khang, "Business-IT alignment: A practical research approach," The Journal of High Technology Management Research, vol. 25, no. 2, pp. 132-147, 2014.

[22] M. El-Mekawy, L. Rusu, E. Perjons, K.-J. Sedvall, and M. Ekici, "Strategic and tactical business-IT alignment barriers in organizations acting in Sweden," International Journal of IT/Business Alignment and Governance (IJITBAG), vol. 6, no. 2, pp. 31-55, 2015.

[23] F. Rahimi, C. Møller, and L. Hvam, "Business process management and IT management: The missing integration," International Journal of Information Management, vol. 36, no. 1, pp. 142-154, 2016.

[24] L. Sun, K. Liu, D. I. Jambari, and V. Michell, "Evaluating business value of IT towards optimisation of the application portfolio," Enterprise Information Systems, vol. 10, no. 4, pp. 378-399, 2016.

[25] H. Kivijärvi, "Advancing organizational alignment decisions: Insights from the structural alignment theory to the business-IT alignment problem," International Journal of IT/Business Alignment and Governance (IJITBAG), vol. 9, no. 1, pp. 53-80, 2018

[26] J. Luftman, K. Lyytinen, and T. b. Zvi, "Enhancing the measurement of information technology (IT) business alignment and its influence on company performance," Journal of Information Technology, vol. 32, no. 1 , pp. 26-46, 2017.

[27] A. Dent, "Aligning IT and business strategy: An Australian university case study," Journal of Higher Education Policy and Management, vol. 37, no. 5, pp. 519-533, 2015.

[28] S. Jorfi, K. M. Nor, and L. Najjar, "An empirical study of the role of IT flexibility and IT capability in IT-business strategic alignment," Journal of Systems and Information Technology, vol. 19, no. 1/2, pp. 2-21, 2017.

[29] S. Panda and S. K. Rath, "Strategic IT-business alignment and organizational agility: From a developing country perspective," Journal of Asia Business Studies, vol. 12, no. 4, pp. 422-440, 2018.

[30] R. van de Wetering, "Modeling alignment as a higher order nomological framework," in International Conference on Business Information Systems, pp. 111-122, Springer, 2016.

[31] K. Zolper, D. Beimborn, and T. Weitzel, "The effect of social network structures at the business/IT interface on IT application change effectiveness," Journal of Information Technology, vol. 29, no. 2, pp. 148-169, 2014.

[32] F. Amarilli, M. Van Vliet, and B. Van den Hooff, "An explanatory study on the co-evolutionary of business IT alignment," in Proceedings of the International Conference on Information Systems (ICIS), pp. 1-21, Association for Information Systems. AIS Electronic Library (AISeL), 2017.

[33] T. Kude, M. Lazic, A. Heinzl, and A. Neff, "Achieving IT-based synergies through regulation-oriented and consensus-oriented IT governance capabilities," Information Systems Journal, vol. 28, no. 5, pp. 765-795, 2018. 
[34] P. Reynolds and P. Yetton, "Aligning business and IT strategies in multi-business organizations," Journal of Information Technology, vol. 30, no. 2, pp. 101-118, 2015.

[35] S. P.-J. Wu, D. W. Straub, and T.-P. Liang, "How information technology governance mechanisms and strategic alignment influence organizational performance: Insights from a matched survey of business and IT managers.," MIS Quarterly, vol. 39, no. 2 , pp. $497-518,2015$.

[36] R. van de Wetering, P. Mikalef, and A. Pateli, "Strategic alignment between IT flexibility and dynamic capabilities: An empirical investigation," International Journal of IT/Business Alignment and Governance (IJITBAG), vol. 9, no. 1, pp. 1-20, 2018.

[37] J. L. Sousa and R. J. Machado, "Sociomaterial enactment drive of business/IT alignment: From small data to big impact," Procedia Technology, vol. 16, pp. 569-582, 2014.

[38] Y. J. Moon, M. Choi, and D. J. Armstrong, "The impact of relational leadership and social alignment on information security system effectiveness in korean governmental organizations," International Journal of Information Management, vol. 40, pp. 54-66, 2018.

[39] F. Schlosser, D. Beimborn, T. Weitzel, and H.-T Wagner, "Achieving social alignment between business and IT: An empirical evaluation of the efficacy of IT governance mechanisms," Journal of Information Technology, vol. 30, no. 2, pp. 119-135, 2015.

[40] S. Bagheri, R. J. Kusters, and J. J. Trienekens, "Business-IT alignment in pss value networks-linking customer knowledge management to social customer relationship management.," in Proceedings of the ICEIS (3), pp. 249-257, 2015.

[41] S. Héroux and A. Fortin, "The moderating role of IT-business alignment in the relationship between IT governance, IT competence, and innovation," Information Systems Management, vol. 35, no. 2, pp. 98-123, 2018.

[42] Y. K. Isal, G. P. Pikarti, A. N. Hidayanto, and E. Y. Putra, "Analysis of IT infrastructure flexibility impacts on IT-business strategic alignment," Journal of Industrial Engineering and Management (JIEM), vol. 9, no. 3, pp. 657-683, 2016.

[43] N. A. Ismail and M. King, "Factors influencing the alignment of accounting information systems in small and medium sized malaysian manufacturing firms," Journal of Information Systems and Small Business, vol. 1, no. 1-2, pp. 1-20, 2014.

[44] P. Malta and R. D. Sousa, "Process oriented approaches in enterprise architecture for business-IT alignment," Procedia Computer Science, vol. 100, pp. 888-893, 2016.

[45] E. Z. Milian, M. de Mesquita Spínola, and M. S. de Paula Pessôa, "Opportunities for strategic alignment of IT to business with the adoption of cloud computing: Case studies in large organizations," in Proceedings of the Portland International Conference on Management of Engineering and Technology (PICMET), pp. 64-74, IEEE, 2015.

[46] M. Queiroz, "Mixed results in strategic IT alignment research: A synthesis and empirical study," European Journal of Information Systems, vol. 26, no. 1, pp. 21-36, 2017.
[47] A. Weeger and H. Ulrich, "How contradictions facilitate evolutionary transformation: An exploration into the dynamics of business-IT alignment from the perspective of activity theory," in Proceedings of the 25th European Conference on Information Systems (ECIS), Association for Information Systems. AIS Electronic Library (AISeL), 2016.

[48] D. Öri and Z. Szabó, "Discovering and analyzing alignment problems in a public organization," in Proceedings of the International Conference on Electronic Government and the Information Systems Perspective, pp. 71-85, Springer, 2018.

[49] A. Benkhayat, A. El Manouar, and H. Sadok, "Firm business strategy and IT strategy alignment: A proposal of a new model," in Proceedings of the 10th International Scientific and Technical Conference" Computer Sciences and Information Technologies"(CSIT), pp. 172-178, IEEE, 2015.

[50] P. Bhattacharya, "Aligning enterprise systems capabilities with business strategy: An extension of the strategic alignment model (sam) using enterprise architecture," Procedia Computer Science, vol. 138, pp. 655-662, 2018.

[51] L. Cuenca, A. Boza, A. Ortiz, and J. JM Trienekens, "Business-IT alignment and service oriented architecture," in Proceedings of the 16th International Conference on Enterprise Information Systems-Volume 3, pp. 490-495, SCITEPRESS-Science and Technology Publications, Lda, 2014

[52] K. Imgharene, K. Doumi, and S. Baina, "Toward a model of agility and business IT alignment," in Proceedings of the International Conference on Big Data, Cloud and Applications, pp. 406-416, Springer, 2018.

[53] J. J. Trienekens, R. J. Kusters, and L. Cuenca, "Measuring business-IT alignment, framework development and case study results," in Information System Development, pp. 1-16, Springer, 2014.

[54] R. Woitsch and W. Utz, "Business process as a service: Model based business and IT cloud alignment as a cloud offering," in Proceedings of the International Conference on Enterprise Systems (ES), pp. 121-130, IEEE, 2015.

[55] I. Zikra, "The communicative nature of information systems integration as an enabler for business IT alignment," in Proceedings of the International Conference on Business Information Systems, pp. 136-147, Springer, 2016.

[56] S. Vander Elst and F. De Rynck, "Alignment processes in public organizations: An interpretive approach," Information Polity, vol. 19, no. 3, 4, pp. 195-206, 2014.

[57] Y. Bartens, F. Schulte, and S. Voß, "Business/IT alignment in two sided markets: A study of cobit 5 for internet based business models," International Journal of IT/Business Alignment and Governance (IJITBAG), vol. 5, no. 2, pp. 27-43, 2014.

[58] A. Buchalcevova and J. Pour, "Business-IT alignment within the management of business informatics model.," in Proceedings of the ICEIS (2), pp. 696-703, 2018.

[59] F. Fattah and A. A. Arman, "Business-IT alignment: Strategic alignment model for healthcare (case study in hospital bandung area)," in Proceedings of the International Conference on ICT For Smart Society (ICISS), pp. 256-259, IEEE, 2014.

[60] K. Hinkelmann and A. Pasquini, "Supporting business and IT alignment by modeling business and IT strategy 
and its relations to enterprise architecture," in 2014 Enterprise Systems Conference, pp. 149-154, IEEE, 2014.

[61] J. Kaidalova, E. Lewańska, U. Seigerroth, and N. Shilov, "Interrelations between enterprise modeling focal areas and business and IT alignment domains," in Proceedings of the International Conference on Business Information Systems, pp. 273-284, Springer, 2015.

[62] M. A. Rakgoale and J. C. Mentz, "Proposing a measurement model to determine enterprise architecture success as a feasible mechanism to align business and IT," in Proceedings of the International Conference on Enterprise Systems (ES), pp. 214-224, IEEE, 2015.

[63] R. Klischewski and A. A. Elragal, "Business-IT alignment in the arab world-is there a fast track to maturity?," in Proceedings of the 24th European Conference on Information Systems (ECIS), Association for Information Systems. AIS Electronic Library (AISeL), 2015.

[64] K. Kritikos, E. Laurenzi, and K. Hinkelmann, "Towards business-to-IT alignment in the cloud," in Proceedings of the European Conference on Service-Oriented and Cloud Computing, pp. 35-52, Springer, 2017.

[65] M. G. Plomp and R. S. Batenburg, "Interorganisational information systems maturity: Do supply chain integration and business/IT alignment coincide?," in Proceedings of Bled e Conference, p. 41, 2014.

[66] A. Rozendal, E. T. Lim, and C.-W. Tan, "A change for the better: Realizing business-IT alignment through organizational change," in Proceedings of the 23rd European Conference on Information Systems (ECIS), Association for Information Systems. AIS Electronic Library (AISeL), 2015.

[67] N. R. P. Senja and B. Pharmasetiawan, "Assessing the relationship among alignment business and information technology, organization culture, and information technology effectiveness," in 2017 International Conference on ICT For Smart Society (ICISS), pp. 1-5, IEEE, 2017.

[68] O. El-Telbany and A. Elragal, "Business-information systems strategies: A focus on misalignment," Procedia Technology, vol. 16, pp. 250-262, 2014.

[69] D. Jelonek, "Self-assessment of the maturity of management information systems-business alignment," in Proceedings of the 6th International Conference on Information Technology: IoT and Smart City, pp. 235-239, ACM, 2018.

[70] Z. Shao, T. Wang, and Y.-q. Feng, "Impact of IS-business strategy alignment and environmental uncertainty on enterprise systems assimilation," in Proceedings of the International Conference on Management Science and Engineering (ICMSE), pp. 1511-1517, IEEE, 2016.

[71] N. Taskin, J. Verville, and T. Keskin, "Strategic alignment of enterprise systems and business strategies under systems and bivariate approaches," in 2014 47th Hawaii International Conference on System Sciences, pp. 4034-4043, IEEE, 2014.

[72] M. El-Mekawy, L. Rusu, and E. Perjons, "An evaluation framework for comparing business-IT alignment models: A tool for supporting collaborative learning in organizations," Computers in Human Behavior, vol. 51, pp. 1229-1247, 2015.

[73] C. Alaceva and L. Rusu, "Barriers in achieving business/IT alignment in a large Swedish company: What we have learned?," Computers in human behavior, vol. 51, pp. 715-728, 2015.
[74] W. A. Bishop, "Addressing the challenge of strategic alignment faced by small and medium-sized entities during the selection of accounting software packages," The International Business \& Economics Research Journal (Online), vol. 16, no. 1, p. 31, 2017.

[75] H.-T. Wagner, "Evolvement of business-IT alignment over time: A situated change perspective," in Proceedings of the 47th Hawaii International Conference on System Sciences, pp. 4366-4375, IEEE, 2014.

[76] E. W. Baker and F. Niederman, "Integrating the IS functions after mergers and acquisitions: Analyzing business-IT alignment," The Journal of Strategic Information Systems, vol. 23, no. 2, pp. 112-127, 2014.

[77] T. Muzira and L. D. Erasmus, "Narrative enquiry into service excellence in uncertainty: Contributions of business and information technology strategic alignment in Zimbabwe," in Proceedings of the Portland International Conference on Management of Engineering and Technology (PICMET), pp. 1867-1877, IEEE, 2016.

[78] C. Z. Tu, Y. Yuan, N. Archer, and C. E. Connelly, "Strategic value alignment for information security management: A critical success factor analysis," Information \& Computer Security, vol. 26, no. 2, pp. 150-170, 2018.

[79] M. El Mekawy, B. AlSabbagh, and S. Kowalski, "The impact of business-IT alignment on information security process," in International Conference on HCI in Business, pp. 25-36, Springer, 2014.

[80] G. W. Jackson and S. S. Rahman, "Security governance, management and strategic alignment via capabilities," in Proceedings of the International Conference on Computational Science and Computational Intelligence (CSCI), pp. 44-49, IEEE, 2017.

[81] M. Queiroz, T. Coltman, P. Tallon, R. Sharma, and P. Reynolds, "The complementarity of corporate IT alignment and business unit IT alignment: An analysis of their joint effects on business unit performance," in Proceedings of the 51st Hawaii International Conference on System Sciences, 2018.

[82] Y. Rahrovani, A. Kermanshah, and A. Pinsonneault, "Aligning IT for future business value: Conceptualizing IT project portfolio alignment," ACM SIGMIS Database: The DATABASE for Advances in Information Systems, vol. 45, no. 3, pp. 30-53, 2014.

[83] A. Vermerris, M. Mocker, and E. Van Heck, "No time to waste: The role of timing and complementarity of alignment practices in creating business value in IT projects," European Journal of Information Systems, vol. 23, no. 6, pp. 629-654, 2014.

[84] J. Vollmar and S. Horn, "Data driven strategy implementation in engineering: Strategic alignment of improvement projects," in Proceedings of International Symposium on Systems Engineering (ISSE), pp. 1-4, IEEE, 2016.

[85] B. Fritscher and Y. Pigneur, "A visual approach to business IT alignment between business model and enterprise architecture," International Journal of Information System Modeling and Design (IJISMD), vol. 6 , no. 1, pp. 1-23, 2015.

[86] C. T. Street, B. Gallupe, and J. Baker, "Strategic alignment in SMEs: Strengthening theoretical foundations.," Communications of Association for Information Systems, vol. 40, p. 20, 2017. 
[87] H. Liang, N. Wang, Y. Xue, and S. Ge, "Unraveling the alignment paradox: How does business-IT alignment shape organizational agility?," Information Systems Research, vol. 28, no. 4, pp. 863-879, 2017.

[88] M. Alaeddini, H. Asgari, A. Gharibi, and M. R. Rad, "Leveraging business-IT alignment through enterprise architecture: An empirical study to estimate the extents," Information Technology and Management, vol. 18, no. 1, pp. 55-82, 2017.

[89] T. Coltman, P. Tallon, R. Sharma, and M. Queiroz, "Strategic IT alignment: Twenty-five years on," Journal of Information Technology, vol. 1, no. 10, pp. 91-100, 2015.

[90] A. A. Alsolamy, U. A. Khan, and P. Khan, "IT-business alignment strategy for business growth," in Proceedings of the International Conference on Computing for Sustainable Global Development (INDIACom), pp. 364-366, IEEE, 2014.

[91] M. Milovich, D. E. Leidner, and D. S. Preston, "The influence of middle management on information technology alignment," in Proceedings of the 48th Hawaii International Conference on System Sciences, pp. 4585-4594, IEEE, 2015.

[92] M. El-Mekawy, L. Rusu, E. Perjons, K.-J. Sedvall, and M. Ekici, "From theory to practice: Barriers to business-IT alignment in organizations acting in Sweden," in Proceedings of the 48th Hawaii International Conference on System Sciences, pp. 4523-4533, IEEE, 2015.

[93] J. Ohlsson, S. Han, M. Hultin, and B. Rosengren, "How to achieve sustainable business IT alignment: Designing a circular organizational structure at SAAB," in Proceedings of the 49th Hawaii International Conference on System Sciences (HICSS), pp. 5116-5125, IEEE, 2016.

[94] M. El-Mekawy, L. Rusu, and E. Perjons, "The impact of business-IT alignment on organizational culture," in Proceedings of the Pacific Asia Conference on Information Systems, 2014.

[95] B. R. Katzy, G. Sung, and K. Crowston, "Alignment in an inter-organisational network: The case of arc transistance," European Journal of Information Systems, vol. 25, no. 6, pp. 553-568, 2016.

[96] M. Nicho and S. Khan, "IT governance measurement tools and its application in IT-business alignment," Journal of International Technology and Information Management, vol. 26, no. 1, pp. 81-111, 2017.

[97] H.-T. Wagner and J. Meshtaf, "Individual IT roles in business-IT alignment and IT governance," in Proceedings of the 49th Hawaii International Conference on System Sciences (HICSS), pp. 4920-4929, IEEE, 2016.

[98] N. Zhang and B. Liu, "The key factors affecting RPA-business alignment," in Proceedings of the 3rd International Conference on Crowd Science and Engineering, p. 10, ACM, 2018.

[99] J. Pepin, P. André, C. Attiogbe, and E. Breton, "A method for business-IT alignment of legacy systems," in Proceedings of the 17th International Conference on Enterprise Information Systems-Volume 3, pp. 229-237, SCITEPRESS-Science and Technology Publications, Lda, 2015.

[100] F. Wonges, J. Zijlmans, and L. W. Santoso, "The alignment of IT and business strategy at roc leeuwenborgh," in Proceedings of the International
Conference on Soft Computing, Intelligent System and Information Technology (ICSIIT), pp. 208-213, IEEE, 2017.

[101] T. Mettler, R. Fitterer, P. Rohner, and R. Winter, "Does a hospitals IT architecture fit with its strategy? An approach to measure the alignment of health information technology," Health Systems, vol. 3, no. 1, pp. 29-42, 2014.

[102] E. van Blerk, A. De la Harpe, and J. Cronje, "IT alignment intelligence: The role of emotional intelligence in business and IT alignment," in Proceedings of the Artificial Intelligence Technologies and the Evolution of Web 3.0, pp. 351-368, IGI Global, 2015.

[103] W. J. Orlikowski and J. J. Baroudi, "Studying information technology in organizations: Research approaches and assumptions," Information systems research, vol. 2, no. 1, pp. 1-28, 1991.

[104] L. Rusu and G. M. Jonathan, "IT alignment in public organizations: A systematic literature review," in Information Technology Governance in Public Organizations, pp. 27-57, Springer, 2017.

[105] J. Wang and L. Rusu, "Factors hindering business-IT alignment in small and medium enterprises in China," Procedia Computer Science, vol. 138, pp. 425-432, 2018.

[106] M. R. Shihab and I. Rahardian, "Comparing the approaches of small, medium, and large organisations in achieving IT and business alignment," International Journal of Business Information Systems, vol. 24, no. 2, pp. 227-241, 2017.

[107] C. Street, B. Gallupe, and J. Baker, "The influence of entrepreneurial action on strategic alignment in new ventures," The Journal of Strategic Information Systems, vol. 27, no. 1, pp. 59-81, 2018.

[108] I. Ritola, R. Siugzda, and L. Rusu, "The influence of organizational politics on business-IT alignment," International Journal of IT/Business Alignment and Governance (IJITBAG), vol. 7, no. 2, pp. 33-48, 2016.

[109] N. Abdolvand and M. M. Sepehri, "Antecedents of strategic information systems alignment in Iran," Journal of Global Information Technology Management, vol. 19, no. 2, pp. 80-103, 2016.

[110] G. J. Kaur and M. H. M. Nor, "Revisiting strategic alignment maturity: Initial evaluation of Malaysian technical vocational education and training institutions," in Proceedings of the IEEE Conference on e-Learning, e-Management and e-Services (IC3e), pp. 108-113, IEEE, 2017.

[111] G. M. Jonathan and L. Rusu, "IT governance in public organizations: A systematic literature review," International Journal of IT/Business Alignment and Governance (IJITBAG), vol. 9, no. 2, pp. 30-52, 2018.

[112] K. Walser, D. Weibel, B. Wissmath, S. Enkerli, N. Bigler, and M. Topfel, "Business-IT alignment in municipalities: The Swiss case," in Proceedings of the 22nd Americas Conference on Information Systems (AMCIS), pp. 1-10, Association for Information Systems. AIS Electronic Library (AISeL), 2016.

[113] G. M. Jonathan, "Influence of organizational structure on business-IT alignment: What we do (not) know," in Proceedings of the 17th International Conference Perspectives in Business Informatics Research (BIR 2018), Stockholm, Sweden, pp. 375-386, CEUR-WS. org, 2018. 